\title{
Discontinuous Control Analysis for Step Down DC-DC Voltage Converters
}

\author{
Bashar F. Midhat ${ }^{1}$ \\ Control and Systems Engineering Department, University of Technology, Baghdad, Iraq \\ 60170@uotechnology.edu.iq
}

\begin{abstract}
The DC-DC power converters have extreme importance in contemporary applications. Moreover, the DC-DC power converters are the ideal candidates in numerous applications such as electric and hybrid vehicles, fuel cells and others. They have been extensively researched upon over three decades. The control of these converters has been often implemented using $P W M$ techniques and based on discrete components and integrated circuits. In this paper we propose a systematic approach for the control of step down DCDC converters with variable input voltage based on discontinuous control action. We demonstrate that the proposed algorithm achieves robustness to variations of the converter load and the input voltage without additional sensors.
\end{abstract}

Index Terms - step down converter, discontinuous control, Lyapunov stability.

\section{INTRODUCTION}

Step down DC-DC converters are used in applications where the required output voltage is lower than the source voltage [1]. The difficulty in the control of DC-DC converters is due to their non-minimum phase structure since the control input appears both in voltage and current equations [2, 3].

As DC-DC converters are nonlinear and time variant systems, the application of linear control techniques for the control of these converters are not suitable $[4,5]$. In order to design a linear control system using classical linear control techniques, the small signal model is derived by linearization around a precise operating point from the state space average model [6, 7, and 8]. The controllers based on these techniques are simple to implement, however, it is difficult to account for the variation of systemparameters, because of the dependence of small signal model parameters on the converter operating point $[9,10]$. Variations of system parameters and large signal transients such as those produced in the startup or against changes in the load cannot be dealt with in these techniques [11]. Multiloop control techniques, such as current mode control, have greatly improved the dynamic behavior, but the control design remains difficult especially for higher order converter topologies [12]. Control techniques suitable for DC-DC converters must cope with their intrinsic nonlinearity and wide input voltage and load variations, ensuring stability in any operating condition while providing fast transient response [9]. Since switching converters constitute a case of variable structure systems, the sliding mode control technique can be a possible option to control this kind of circuits [13]. The use of sliding mode control enables to improve and even overcome the deficiency of the control method based on small signal models [14, 15]. In particular, sliding mode control improves the dynamic behavior of the system, endowing it with characteristics such as robustness against changes in the load, uncertain system parameters and simple implementation [16,17].

In this paper, the application of discontinuous control for step down DC-DC voltage converters has been analyzed. The operation and mathematical model for the converter have been described in section II. In section III, the analysis for the control is made. Simulations are performed in section IV and some conclusions are made in section $\mathrm{V}$. 


\section{MODELLING OF STEP DOWN DC-DC CONVERTER}

The topology of step down converter is shown in Fig. 1. When the switch is on position 1 the circuit is connected to the DC input source resulting in an output voltage across the load resistor. If the switch changes its position to position 2, the inductor current will discharge through the load. Controlling switch position the outpt voltage can be maintained at a desired level lower than the input source voltage.

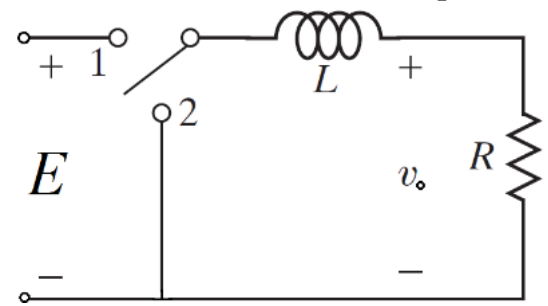

Fig. 1. SCHEMATIC OF CONVENTIONAL STEP-DOWN DC-DC VOLTAGE CONVERTER [1].

For a negligible1 resistance offered by DC-DC converter inductor, the depicted DC-DC step down converter (Fig.1) can be described by the following equation:

$$
L \frac{d l}{d t}=u E-v_{o}
$$

where $I$ is the converter current (Amp), $L$ and $R$ are the inductance (Henry) and load resistance (Ohm), respectively, $E$ and $v_{a}$ are input source and output voltages (Volts), respectively, and $u$ is the control input, or a switching function, which can acquire two discrete values - either 0 or 1.

For control purposes, the model of (1) can be written in terms of input voltage $E$ and output voltage $v_{a}$ only as following:

Applying Ohm’s law we get

$$
I=\frac{v_{o}}{R}
$$

Derive the above equation once

$$
\frac{d l}{d t}=\frac{v_{a}}{R}
$$

Substitute for $\frac{d v}{d t}$ in (1)

$$
\frac{L}{R} v_{0}=u E-v_{0}
$$

Rearranging the above equation one can get

$$
v_{o}=-\frac{R}{L_{1}} v_{o}+\frac{R}{l_{0}} u E
$$

For simplicity in notation, the above equation will be referred to the state space model described by (3) below

$$
x=-a x+a u E
$$

where $x=v_{o}$ and $a=\frac{R}{R}$

\section{DICONTINUOUS CONTROL ANALYSIS}

The first step in designing the controller is to define an error function e

$$
\Theta=x_{d}-x
$$


where $x_{d \varepsilon}=v_{d d}$, also, as the switching control may have values only 1 or 0 , then the control action $u$ can be written as

$$
u=\frac{1}{2}(1+\operatorname{sign}(\theta))
$$

Substitute for u and $x=x_{d}-$ from (4) and (5) into (3)

$$
\begin{gathered}
x=-a x+a E \frac{1}{2}(1+\operatorname{sign}(\theta)) \\
=-a\left(x_{d}-\theta\right)+\frac{1}{2} a E+\frac{1}{2} a E \operatorname{sign}(\theta) \\
x=-a x_{d}+\frac{1}{2} a E+a \theta+\frac{1}{2} a E \operatorname{sign}(\theta)
\end{gathered}
$$

Derive (4) once and substitute for $\dot{x}$

$$
\S=x_{d}-x^{2}=x_{d}-\alpha x_{d}-\frac{1}{2} \alpha E+\alpha e-\frac{1}{2} \alpha E \operatorname{sign}(\theta)
$$

To investigate the stability of the converter under the proposed control action $u$, the Lyapunov stability criterion is applied.

First, define a positive definite Lyapunov function

$$
V=\frac{1}{2} e^{2}
$$

Then, the system is considered stable if the Lyapunov function time derivative is negative definite, to do so, derive (7) once with respect to time

$$
V=e \Leftrightarrow 0
$$

Substitute for $\dot{e}$ from (6) into (7)

$$
\begin{aligned}
& V=e \dot{V}=e\left[x_{d}+a x_{d}-\frac{1}{2} \alpha E-\alpha e-\frac{1}{2} \alpha E \operatorname{sign}(\theta)\right]<0 \\
& V=e x_{d e}+a e x_{d}-\frac{1}{2} a E \theta-a e^{2}-\frac{1}{2} a E|e|<0
\end{aligned}
$$

Applying the triangle inequality [18], the above equation can be rewritten as

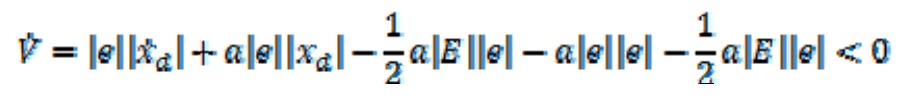

Noticing that

$$
\|\theta\|>0 \forall \theta \neq 0
$$

Then

$$
\begin{gathered}
\left|x_{d \varepsilon}\right|+a\left|x_{d}\right|-\frac{1}{2} a|E|-a|e|-\frac{1}{2} a|E|<0 \\
\left|x_{d}\right|+a\left|x_{d}\right|-a|e|-a|E|<0
\end{gathered}
$$

Finally, we get

$$
|E|>\frac{1}{\pi}\left|x_{d}\right|+\left|x_{d}\right|-|e|
$$

The above inequality can have an upper bound when ${ }^{e}=0$, which results in 


$$
\left|E \|>\frac{1}{a}\right| x_{d}|+| x_{d} \mid
$$

If the desired output voltage is assumed to be constant, then $x_{d \dot{d}}=0$, which makes the final conclusion

$$
\|E\|>\| x_{d} \mid
$$

The inequality (11) simply shows that, in case that the desired output voltage is constant, then the converter is able to give an output voltage equals to the desired as long as the supply voltage is greater than the desired.

\section{SIMULATION AND RESULTS}

The proposed control is applied to a conventional step-down converter in simulation using MATLAB. The converter inductance is assumed to have a value of $100 \mathrm{mH}$ and applied to a resistive load of 10 Ohms and the desired output voltage is 5 volts and the sampling time of the simulations is set to $1 \mathrm{~ms}$.

In the first simulation, it is assumed that the supply voltage $\mathrm{E}$ has a constant value of 12 Volts. Figs 2, 3, 4 and 5 show the output voltage, load current and control signal, respectively.

Since the control signal in Fig. 4. is hard to recognize, another plot is added to show the equivalent control signal, and this is done by filtering the control signal shown in Fig. 4, using a low pass filter and the resulting signal is plotted in Fig. 5.

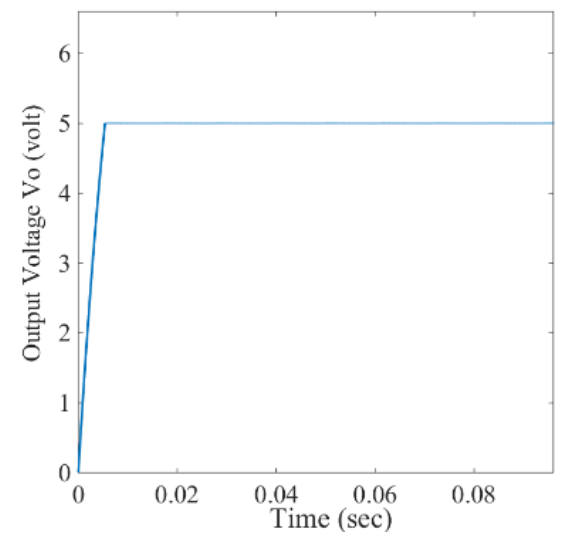

Fig. 2. OUtPUt VOLTAGE.

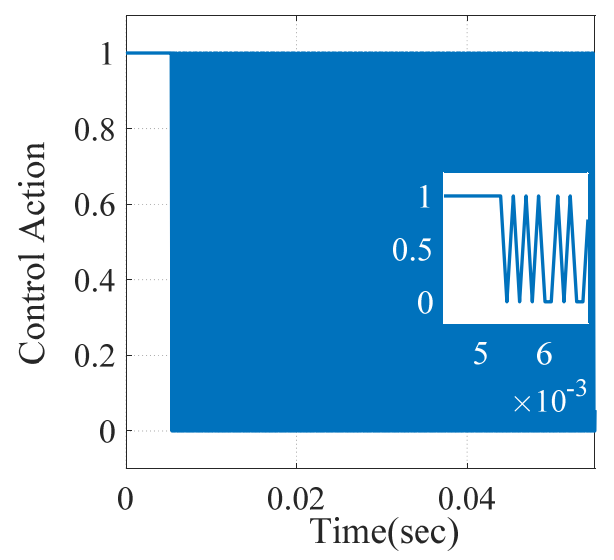

FIG. 4. CONTROL ACTION.

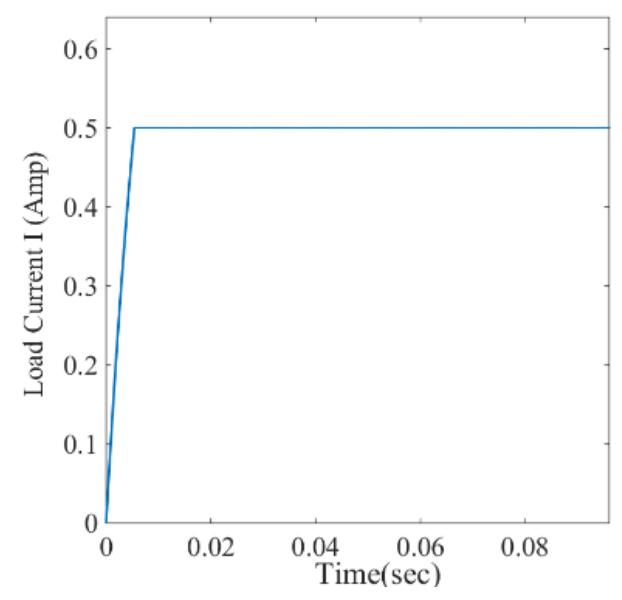

FIG. 3. LOAD CURRENT.

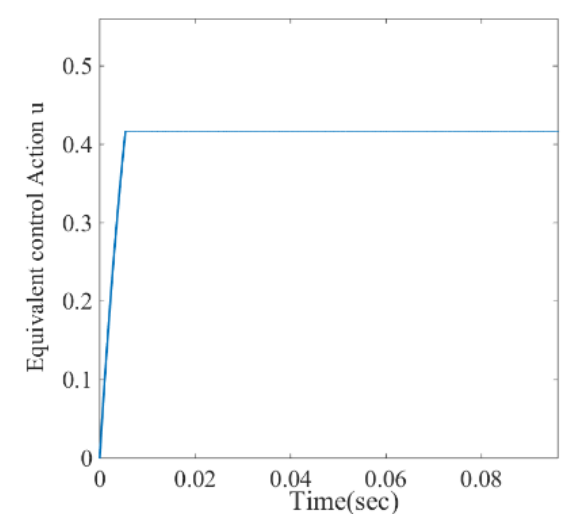

FIG. 5. EQUIVALENT CONTROL ACTION. 
In the second simulation, it is assumed that the supply voltage is variable or subjected to disturbance and described as $E=12+3 \sin (100 t)$, Figs. 6-11 show the results.

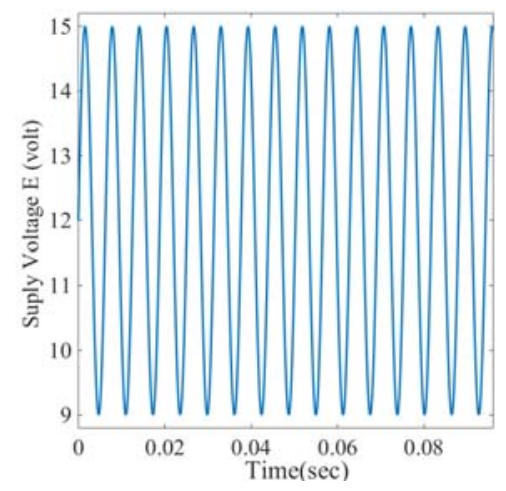

FIG. 6 SUPPLY VOLTAGE.

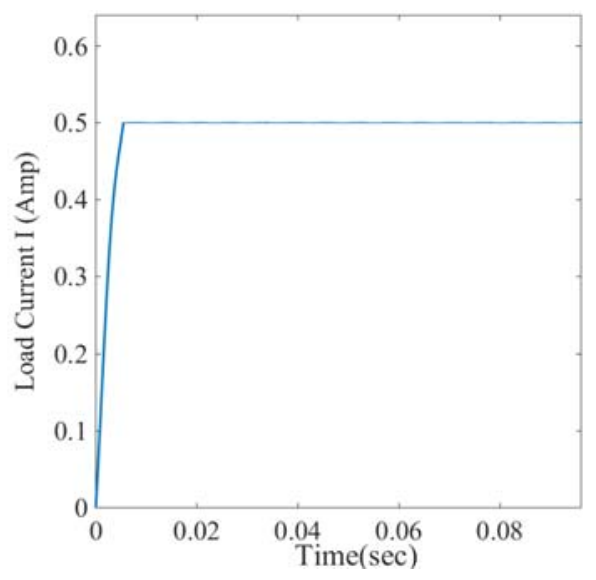

FIG. 8. LOAD CURRENT.

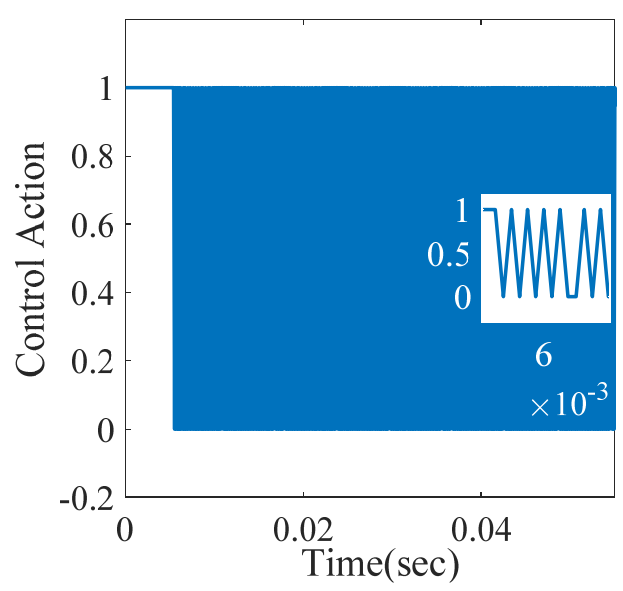

FIG. 10. CONTROL ACTION.

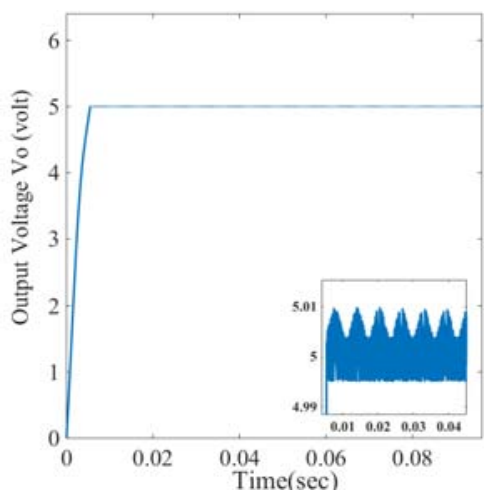

Fig. 7. OUtPUT VOLTAGE.

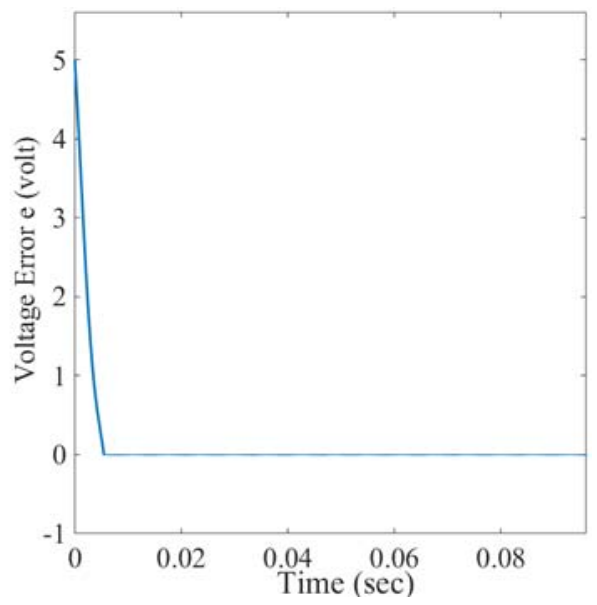

FIG. 9. VOLTAGE ERROR.

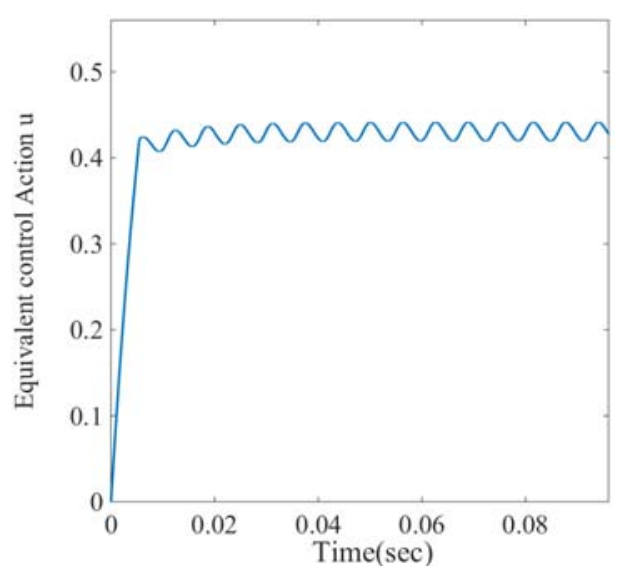

FIG. 11. EQUIVALENT CONTROL ACTION.

A third simulation is performed to show the effect of load variation on the performance of the converter. In this simulation, the supply voltage $E$ is assumed to be constant at 12 volts but the load 
value changes suddenly from 10 to 5 ohms. Fig's 12-15 show the results. Fig. 15 shows the load value changes.

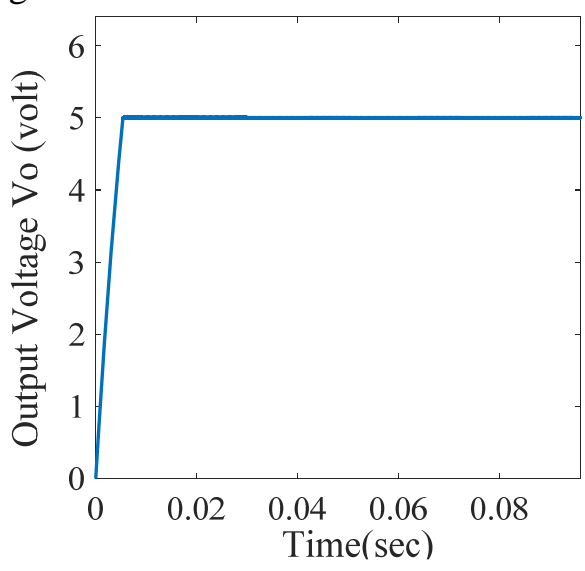

Fig. 12. OutPut Voltage.

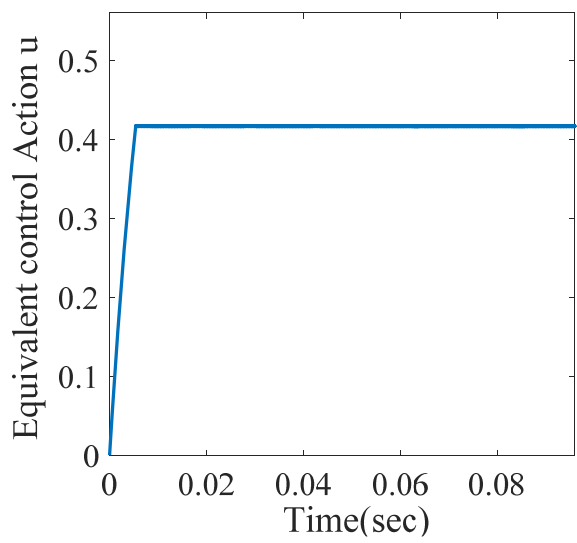

FIG. 14. EQUIVALENT CONTROL ACTION.

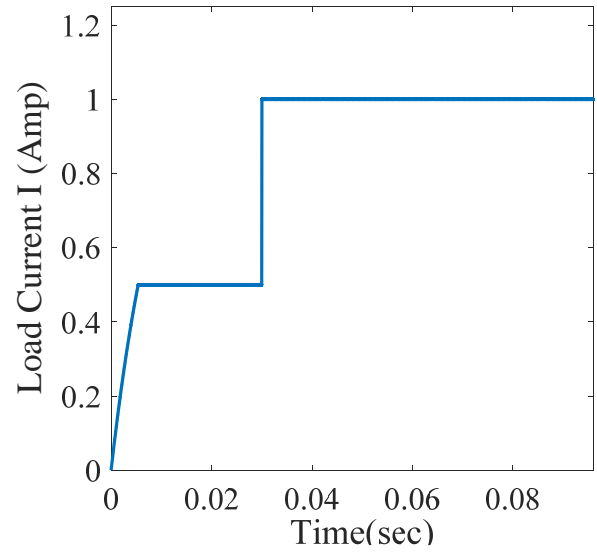

FIG. 13. LOAD CURRENT.

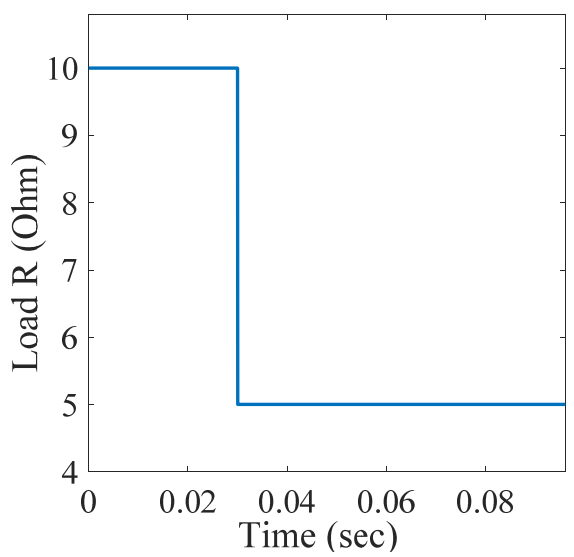

FIG. 15. LOAD RESISTANCE.

\section{CONCLUSIONS}

In this paper an analysis for step down DC-DC voltage converters under discontinuous control has been made where the Lyapunov stability criterion has been applied to determine the ability of the converter to give the desired output voltage. The results show that the converter is able to give the desired output voltage whenever the condition developed by (11) is satisfied which proves the validity of the theoretical part of the analysis. It's important to mention that, due to the switching nature of the circuit which is imposed by the on/off switch, then some ripple will appear in the output signal which has a value about \pm 0.001 volts in this work. However, the output ripple can be reduced using a larger value for the inductor $L$ which is primarily used to filter out the high frequency component in the output signal. Another important factor is the switching frequency which is directly affected by the circuit sampling time. In this work, the sampling time was chosen to have a value of $1 \mathrm{~ms}$ which results in some ripple in the output signal. On the other hand, choosing a smaller sampling time value will result in less ripple in the output signal but also a higher switching frequency which might be beyond the switch limitations in practical applications.

\section{REFERENCES}

[1] M. H. Rashid, Power Electronics, Pearson, 2014.

[2] J. Clerck Maxwell, Control Design Techniques in Power Electronics Devices, Springer, New York, USA, 2006.

[3] A. I. Pressman, Switching Power Supply Design, McGrew Hill, New York, NY, USA, 2nd edition, 1998.

[4] J. A. A. Qahouq, O. Abdel-Rahman, L. Huang, and I. Batarseh, "On load adaptive control of voltage regulators for power managed loads: Control schemes to improve converter efficiency and performance,” IEEE Transactions on Power Electronics, vol. 22, no. 5, 2007, pp. 1806-1819. 
[5] A.J. Foreyth and S.V. Mollov, "Modeling and control of DC-DC converters", IEEE Power EngineeringJournal , vol. 12 no. 5, 1998, pp 229-236.

[6] J. H. Su, J. J. Chen, and D. S. Wu, "Learning feedback controller design of switching converters via MATLAB/SIMULINK,” IEEE Transactions on Education, vol. 45, no. 4, 2002, pp. 307-315.

[7] L. Guo, J.Y. Hung and R. M. Nelms, "Design and implementation of a digital PID controller for a buck converter," Proceedings of the 36th Intersociety Energy Conversion Engineering Conference, July/August 2001, vol. 1, pp. 187-192.

[8] H. Mingzhi and X. Jianping, "Nonlinear PID in Digital Controlled Buck Converters", Applied power electronics conference APEC 2007, 25 Feb-1 March 2007, Anahein CA USA, pp. 1461-1465.

[9] Mattavelli. P., L. Rosetto and G. Spiazzi. “Small signal analysis of DC-DC converters with sliding mode control”. IEEE Transactions on Power Electronics. 12: 96-102, 1997.

[10] S. Arulselvi, G. Uma and M. Chidambaram, "Design of PID controller for boost converter with RHS zero", 4th International Power Electronics and Motion Control Conference (IPEMC 2004), China, 14-16, 2004.

[11] M. Ahmed, M. Kuisma, P. Silventoinen, "Comparison between PID Control and Sliding Mode Control for Buck Converter", Proceedings of the Symposium on Power Electronics, Electrical Drives, Automation and Motion. Speedam 2004. Capri - Italy, 16-18 June 2004.

[12] Matas. J . L.G. Vicuna. o. Lopez. M. Lopez and M. Castilla. Sliding-LQR based control of DC-DC converters. European Power Electronics Conference (EPE·99) , 1999.

[13] Lopez, M., LG. Vicuna, M Castilla, 0. Lopez and J. Matas, 1999. Sliding mode control strategy applied to parallel connected converters. European Power Electroincs Conference (EPE'99).

[14] Siw-Chong Tan, Y.M Lai, Chi K.Tse, "General Design Issues of Sliding-Mode Controllers in DC-DC Converters", IEEE transactions On Industrial Electronics, vol. 55, no. 3, March 2008.

[15] G. Spiazzi, P. Mattavelli and L. Rossetto, "Sliding control of DC-DC converters", 4 Congresso Brasileiro de Elettronica de Potencia (COBEP), Belo horizonte, December 1997, pp. 59-68.

[16] D. Cortes and J. Alvarez, "Robust sliding mode control for the boost converter", Proceedings of VIII IEEE International Power Electronics Congress, (CIEP 2002), 20-24 October 2002, pp. 208 - 212.

[17] S-C Tan, Y.M Lai, Chi K Tse, Luis Martniez Slamero, Chi-Kin Wu, "A Fast response sliding mode controller for boost type converter with a wide range of operating conditions", IEEE transactions On Industrial Electronics, vol. 54, no. 6, 2007.

[18] George B. Thomas, Maurice D. Weir, Joel R. Hass, Thomas' Calculus: Multivariable, $12^{\text {th }}$ ed. Pearson, USA, 2010.

[19] Sanjeevikumar, P.; Grandi, G.; Wheeler, P.; Blaabjerg, F.; Loncarski, J. A “simple mPPT algorithm for novel PV power generation system by high output voltage DC-DC boost Converter”. In Proceedings of the $24^{\text {th }}$ Inte-rnational Symposium on Industrial Electronics, Rio de Janeiro, Brazil, 2015; pp. 214-220.

[20] Mahajan, S.B.; Sanjeevikumar, P.; Blaabjerg, F. “A Multistage DC-DC step-up self-balanced and magnetic componentfree converter for photovoltaic application: Hardware implementation”. Energies 2017, 10, 719.

[21] Mahajan, S.B.; Sanjeevikumar, P.; Blaabjerg, F.; Ojo, S.; Seshagiri, S.; Kulkarni, R. "Inverting Nx and 2Nx non isolated multilevel boost converter for renewable energy application”. In Proceedings of the 4th IET International Conference on Clean Energy and Technology, Kuala Lumpur, Malaysia, 14-15 November 2016; pp. 1-8.

[22] Sanjeevikumar, P.; Grandi, G.; Blaabjerg, F.; Wheeler, P.; Siano, P.; Hammami, M. "A Comprehensive Analysis and Hardware Implementation of Control Strategies for High Output Voltage DC-DC Boost Power Converter.” Int. J. Comput. Intell. Syst. 2017, 10, pp.140-152.

[23] Mahajan, S.B.; Sanjeevikumar, P.; Wheeler, P.; Blaabjerg, F.; Rivera, M.; Kulkarni, R. "XY converter family: A new breed of buck boost converter for high step-up renewable energy applications.” In Proceedings of the IEEE International Conference on Automatica, Curico, Chile, 19-21 October 2016; pp. 1-8. 